* Doutora em Ciências Jurídicas e Sociais pela UFF. Professora do Curso de Direito na Faculdade Gama e Souza (RJ) http://lattes.cnpq.

br/6533454338422679

e-mail: marimont28@hotmail.com

**Mestre em Ciências Jurídicas e Sociais pela UFF. Professora da Pós Graduação em Criminologia, Processo e Direito Penal da UCAM (RJ). tp://lattes.cnpq.

br/3281746200455908

e-mail: annacarolinapinto@id.uff.br

\section{Notas Sobre a Separação Constitucional Do Poder Político Como Instrumento De Preservação da LIBERDADE}

\author{
Notes On The Constitutional Separation Of \\ Political Power As An Instrument For The \\ Preservation Of Freedom
}

\section{Mariana Lourenço Monteiro* Anna Carolina Cunha Pinto**}

Como citar: MONTEIRO, Mariana Lourenço; PINTO, Ana Carolina Cunha. Notas sobre a separação constitucional do poder político como instrumento de preservação da liberdade. Revista do Instituto de Direito Constitucional e Cidadania - IDCC, Londrina, v. 5, n. 1, p 140-153, jan/jul, 2020. ISSN: 2596-0075. https://doi.org/10.48159/revistadoidcc.v5n1.monteiro.pinto

Resumo: O presente artigo busca realizar uma exploração teórica da forma como a teoria da separação dos poderes concebida inicialmente como forma de enfraquecer o Estado-, foi se tornando problemática com a evolução da sociedade. $\mathrm{Na}$ medida em que o Estado foi sendo mais e mais demandado, uma legislação mais numerosa e mais técnica foi tornando-se necessária, algo incompatível com os modelos tradicionais de separação de poderes.Concebendo-a como um sistema que conjuga legislativo, executivo e judiciário harmônicos e independentes entre si, Montesquieu não concebeu atribuições internas ao Estado, exceto julgar e punir os indivíduos que não cumprissem as leis - trata-se do Estado mínimo que será consagrado mais adiante pelo liberalismo, não havendo grande preocupação com a sua eficiência até aquele momento (século XVIII), e sim com a garantia da liberdade individual.A despeito de haver contribuído para a conformação dos Estados democráticos modernos, propomos pensar a teoria da separação dos poderes num cenário em que se coloca a questão da eficiência do Estado e de como garanti-la sem atentar diretamente contra a separação dos poderes. Propomos considerar o fato de que tais exigências requerem do Estado um maior dinamismo e sua presença constante na vida social, conciliando a necessidade de eficiência com os princípios democráticos, algo que se incompatibiliza muitas vezes com a tradicional separação de poderes. 
Palavras-chave: Estado. Separação de Poderes. Direito Constitucional. Teoria Geral do Estado.

Abstract: This article seeks to carry out a theoretical exploration of how the theory of the separation of powers - initially conceived as a way of weakening the State - has become problematic with the evolution of society. As the State became more and more demanded, more and more technical legislation became necessary, something incompatible with the models of separation of powers. Conceiving it as a system that combines legislative, executive and judicial systems that are harmonious and independent from each other, Montesquieu did not conceive internal attributions to the State, except to judge and punish individuals who did not comply with the laws. It is the minimum state that will be consecrated later by liberalism, with no great concern with its efficiency until that moment (18th century), but with the guarantee of individual freedom. Despite having contributed to the shaping of modern democratic states, we propose to think of the theory of the separation of powers in a scenario in which the question of the efficiency of the state is posed and how to guarantee it without directly attacking the separation of powers. We propose to consider the fact that such demands require a greater dynamism from the State and its constant presence in social life, reconciling the need for efficiency with democratic principles, something that is often incompatible with the traditional separation of powers.

Keywords: State. Separation of Powers. Constitutional right. General State Theory. 


\section{INTRODUÇÃO}

O presente trabalho versa sobre uma análise interdisciplinar sobre a separação constitucional do poder político, na qual buscamos estabelecer suas bases, por intermédio de contribuições da Ciência Política e da Teoria Geral do Estado, e implicações na atualidade do Direito Constitucional e da sociedade brasileira. Traçamos, ainda, um paralelo com o arcabouço teórico do pensamento de Montesquieu sobre o assunto com a forma como tal separação pode ser verificada na atualidade, com especial auxílio da obra de Ingeborg Maus que versa sobre o papel social desempenhado pelo agigantado poder judiciário que construiu sua auto dispensa ao controle social o que o permite dispensar preceitos da própria constituição incorrendo, assim, em prejuízos à liberdade.

Nossa exploração do tema, circunscrita à análise de bibliografia selecionada de autores de destaque para referida discussão, justifica sua relevância no fato de que os Estados da contemporaneidade ${ }^{1}$ apenas vagamente conservam uma equilibrada separação entre suas funções principais - legislativa, executiva e judiciária - tendo diante de si a difícil tarefa de dosar a ação estatal com vistas a preservar direitos e garantias, liberdade e democracia, sem prejuízo à eficiência.

Uma vez que nossa investigação tem por objetivo problematizar de que forma a teoria da separação dos poderes - concebida inicialmente como forma de enfraquecer o Estado - já não conserva senão distantes traços de sua formulação clássica, parece-nos fundamental que antes que possamos nos dedicar às causas desse desvio, nos esforcemos por recuperar importantes noções e elementos que levaram à formulação mesma da separação dos poderes.

\section{INTERLOCUÇÕES ENTRE CIÊNCIA POLÍTICA, TEORIA GERAL DO ESTADO E ESTADO CONSTITUCIONAL}

Montesquieu foi antecedido por Nicolau Maquiavel (1469-1527), Thomas Hobbes (1588-1679) e John Locke(1632-1704), e sucedido por Jean-Jacques Rousseau (1712-1778), todos contratualistas e preocupados em especial com a natureza do poder político, segundo os quais o contrato social rompe com o estado de natureza, instituindo o estado de sociedade que garanta a estabilidade contra o risco da anarquia ou do despotismo (MENEZES, 2005, p, 245). Maquiavel, por exemplo, refletindo sobre a importância de se evitar o caos resultante da livre expressão da natureza, agindo-se sobre o real de modo a poder organizá-lo e melhor controlá-lo, dirá (MAQUIAVEL, 1994, p.129):

Aquele que estudar cuidadosamente o passado pode prever os acontecimentos que se produzirão em cada Estado e utilizar os mesmos meios que os empregados pelos antigos. Ou então, se não há mais os remédios que já foram empregados, imaginar outros novos, segundo a semelhança dos acontecimentos.

1 Ocidental. 
Hobbes (1988, p. 106), por sua vez, ao conceber o Estado civil como modo de superação do estado de natureza, dirá tratar-se de "uma pessoa de cujos atos uma grande multidão, mediante pactos recíprocos uns com os outros foi instituída por cada um como autora, de modo ela poder usar a força e os recursos de todos, da maneira que considerar conveniente, para assegurar a paz e a defesa comum".

Para Montesquieu o Estado, ou a vida civil, tem muitas formas de se realizar que não se explicam pela natureza do poder político - não se deve procurar explicar a existência de instituições políticas, mas sim o funcionamento destas.

Comumente associado ao desenvolvimento da teoria dos três poderes, a obra de Montesquieu trata da questão do funcionamento dos regimes políticos, dentro de uma ótica liberal. Orientado por questões próprias de um tempo posterior ao seu, buscou fundamentalmente responder à seguinte questão: como dotar de maior estabilidade os regimes que viriam a resultar das revoluções democráticas? No mesmo sentido da estrada já trilhada por Maquiavel, buscou compreender as razões da decadência das monarquias, os conflitos intensos que minaram a sua estabilidade, mas, além disso, os mecanismos que garantiram, por tantos séculos, sua estabilidade. Sua resposta viria em sua tipologia dos governos (ou teoria dos princípios e da natureza dos regimes) e a na sua teoria dos três poderes (ou da separação dos poderes).

A teoria da separação dos poderes ou da equipotência (o mesmo poder a cada um dos poderes) estabelece como base do Estado de Direito a separação dos poderes executivo, legislativo e judiciário, e a independência entre eles.(MENEZES, 2005, p 245) Montesquieu identifica, no entanto, uma necessária imbricação e interdependência das funções. É necessário que um poder possa contrariar outro poder. Para o autor, trata-se de buscar uma instância independente capaz de moderar o poder do rei (do executivo), um problema político de correlação de forças, mais do que uma questão jurídico-administrativa de organizar funções.

O Judiciário é considerado um poder nulo por Montesquieu. Ele afirma que "os juízes (são).a boca que pronuncia as palavras da lei", havendo de fato então apenas dois poderes ou fontes do poder político: o rei, cuja potência provém da nobreza, e o povo ${ }^{2}$. É preciso que a classe nobre, de um lado, e a classe popular, de outro, tenham poderes independentes e capazes de se contrapor. Neste sentido, dirá (MONTESQUIEU, 2006, p. 166)

Quando na mesma pessoa, ou no mesmo corpo de magistrados, o poder legislativo se junta ao executivo, desaparece a liberdade; pode-se temer que o monarca ou o senado promulguem leis tirânicas, para aplicá-las tiranicamente. Não há liberdade se o poder judiciário não está separado do legislativo e do executivo. Se houvesse tal união com o legislativo, o poder sobre a vida e a liberdade dos cidadãos seria arbitrário, já que o juiz seria ao mesmo tempo legislador. Se o judiciário se unisse com o executivo, o juiz poderia ter a força de um opressor. E tudo estaria perdido se a mesma pessoa, ou o mesmo corpo de nobres, de notáveis, ou de populares, exercesse os três poderes: o de fazer as

2 Interessante destacar que à sua época, "povo" designava a burguesia. 
leis, o de ordenar a execução das resoluções públicas e o de julgar os crimes e os conflitos dos cidadãos.(grifos nossos)

Para que seja possível fazermos uma releitura crítica da teoria da separação dos poderes, confrontando-a com as instituições contemporâneas, precisamos inicialmente recuperar de seu idealizador algumas noções fundamentais que servirão de base para nossa reflexão. Primeiramente, a sua visão científica da ideia de lei. A grosso modo, até o século XVIII a noção de lei estava associada a uma ideia de lei de Deus, que exprimia uma certa ordem natural resultante da vontade deste; relacionava-se a um dever-ser (direcionadas a uma finalidade divina) e tinha conotação de expressão de autoridade sendo, por essa razão, legítimas. Nesta perspectiva eram imutáveis porque se situavam dentro de ordem de coisas e eram ideais, já que visavam uma finalidade perfeita.

Montesquieu, diferentemente, introduz seu conceito de lei em O Espírito das Leis (1996), buscando se distanciar da confusão entre as perspectivas política, moral e religiosa de seu tempo, nesta questão. Para tanto, parte da seguinte preliminar: do mesmo modo que existem leis que regem os corpos físicos na natureza, para o autor, também poderíamos encontrar leis que regeriam os costumes e as instituições. Se para os corpos físicos falamos em termos de massa e movimento, para os corpos de natureza política massa e movimento corresponderiam a quem exerce o poder e como ele é exercido. As leis que regem as instituições políticas seriam, por sua vez, relações entre as diversas classes em que se divide a população, as formas de organização econômica, as formas de distribuição do poder, etc. Importante notar que o objeto de Montesquieu não são as leis em geral, mas o espírito das leis, isto é, as relações entre as leis positivas e diversos fatores.

Para que essa virada teórica fosse possível, contudo, foi preciso que uma série de condições se apresentassem e tecessem o pano de fundo para a noção de que era preciso enfraquecer o Estado para se alcançar algo como um bem maior, o bem comum. Podemos apontar, neste sentido, a preliminar montesquiana a respeito das formas de governo, mais fundamentalmente, sua concepção acerca da forma republicana.

Tal qual concebido por Montesquieu, o governo republicano identifica-se como o regime que depende dos homens, que repousa na virtude dos homens, na capacidade destes de colocar o bem público acima do bem próprio. Contudo, tudo parece conspirar contra a prevalência do bem público, sendo fundamental que os homens mais virtuosos contenham seus apetites e os dos demais. A república é, enfim, aquele regime que os grandes não a querem e o povo não sabe mantê-la. A este respeito, dirá Montesquieu que a república é o regime do passado, uma vez que típico das pequenas cidades antigas que se reuniam em pequenos grupos, formados por homens moderados, que possuíam uma certa igualdade de riquezas e de costumes, ditada pela escassez. Com o desenvolvimento do comércio, contudo, e o crescimento das populações, a sociedade se foi dividindo em classes e, com isso, a virtude cívica não pôde prosperar.

A monarquia, diferentemente, não precisa da virtude, inclusive a favorecem paixões 
desonestas da nobreza, ela repousa apenas e tão somente nas instituições. Ela é o governo das instituições, são estas que devem conter os impulsos da autoridade executiva e os apetites dos poderes intermediários - Montesquieu considera que o poder está dividido, o poder contraria o poder, um contém o outro, este é o seu princípio de moderação (que inexiste na república). Enquanto governo das instituições, a monarquia seria, portanto, o regime da realidade ou, de forma mais precisa, do presente.

Finalmente, o despotismo seria, segundo Montesquieu, o governo da paixão, estando condenado à autofagia, levando necessariamente à desagregação ou à rebelião. É a ameaça do futuro, no sentido de que ao abolir os privilégios da nobreza, as monarquias europeias tornavam absoluto o poder do executivo.

Tratando das três formas de governo, em síntese, dirá (MONTESQUIEU, 2006, 19):

O governo republicano é aquele em que todo o povo, ou apenas uma parte do povo, tem o poder soberano; o monárquico, aquele em que uma só pessoa governa, mas por meio de leis fixas e estabelecidas; enquanto, no despótico, uma só pessoa, sem lei e sem regra, tudo conduz, por sua vontade e por seus caprichos.

Com a crescente complexificação das sociedades, a partir do desenvolvimento do comércio, as experiências republicanas vão se tornando frequentes na Europa Ocidental. A partir do XVI já há cidades-República (na Itália) que aparecem como instâncias políticas com autonomia em relação à Igreja Católica. Aos poucos sai de cena a transcendência como dispositivo de justificação e de legitimação do exercício do poder e surge uma nova compreensão de cunho imanente, afirmando um novo mundo onde as sobredeterminações da realidade não faziam mais sentido. Marcado por essa influência, em seu contexto histórico, o século XVIII, Montesquieu estará convencido de que a república é o melhor dos regimes, em que pese ser uma forma de governo naturalmente instável por repousar na virtude dos homens, em quem não se pode depositar muita confiança.

Para remediar tal situação de risco iminente,Montesquieu julga ser necessário que se crie uma estrutura para o exercício do poder político, que o contenha, enfraqueça-o, racionalize seu uso. Um sistema que permita a autonomia das funções (poderes) do Estado sem, contudo, darlhes independência total, permitindo a harmonia entre elas, um certo equilíbrio no uso de suas atribuições - algo que mais tarde se apresentará sob a forma da teoria dos freios e contrapesos.

Para que seja possível compreender como uma tal percepção da necessidade de se enfraquecer o Estado foi possível, vejamos primeiramente como nasce a ideia de que o poder deve ser limitado por uma norma superior, uma Lei fundamental, uma Constituição, em breves apontamentos sobre o surgimento do chamado Estado Constitucional.

\section{O ESTADO CONSTITUCIONAL: RACIONALIZAÇÃO E LIMITAÇÃO DO USO DO PODER}

Criação moderna que surge em paralelo e sob a influência dos mesmos princípios do Estado Democrático, falamos em Estado Constitucional quando o Estado se enquadra em um 
sistema normativo fundamental qualquer, algo que nos remete ao constitucionalismo (DALLARI, 2018, p.196). Existente, ao menos em seus traços mais elementares, desde Antiguidade, o constitucionalismo nasce de fato por volta de 1215 quando da assinatura pelo Rei João Sem Terra da Magna Carta inglesa, autolimitando seus poderes como forma de satisfazer a exigência dos barões. Ainda na Inglaterra, no século XVII, o advento da Revolução Inglesa consagra a supremacia do Parlamento como órgão legislativo, ficando cada vez mais claro que o Estado deveria ter um governo de leis, não de homens. Ser objetivo, não subjetivo ou pessoal (DALLARI, 2018, p.197).

No século seguinte, vários fatores levariam ao aparecimento das Constituições enquanto esse sistema normativo fundamental a que aludimos anteriormente. Fatores como o jusnaturalismo defendido pelos contratualistas, segundo o qual haveria direitos naturais do homem, inalienáveis, que deveriam ser protegidos contra a ação do Estado, consagrando a supremacia do indivíduo (DALLARI, 2018, p.197). Outro fator que determinou o aparecimento das Constituições foi a luta contra o poder absoluto dos monarcas, reivindicando a necessidade da limitação do poder político. Temos aqui algo que se insere na temática ainda mais ampla do Iluminismo enquanto movimento que coroou a crença na razão e a exigência de racionalização do poder.

A racionalização que leva à limitação do uso do poder, protegendo o indivíduo contra o Estado, permite dizer que o constitucionalismo teve mesmo um caráter revolucionário (DALLARI, 2018, p.198). Afinal, foi contra a sua vontade que os monarcas absolutos limitaram seus poderes por meio de Constituições escritas - a opção mais "segura" como forma de assegurar as novas condições políticas contra eventuais abusos e retrocessos. Neste espírito é que foi elaborada a primeira Constituição escrita, do Estado de Virgínia, de 1776, seguida pela dos Estados Unidos, de 1787, a primeira a ser posta em prática de fato, e pela pela Constituição francesa de 1789, a de maior repercussão.

Em que pese suas diferentes características em cada Estado, podemos apontar alguns objetivos comuns do constitucionalismo, como a incorporação do liberalismo político que surgia naquele momento, se conjugando com as lutas em favor dos direitos e liberdades do indivíduo. Importante notar que alguns Estados o constitucionalismo foi o instrumento de afirmação política de novas classes econômicas, quando então teve caráter realmente revolucionário, mudando estruturas e limitando estado e governo, enquanto que, em outros, foi a mera expressão de anseios intelectuais sem caráter utilitarista. Nestes casos, teve caráter apenas simbólico, gerando monarquias constitucionais que perderam o caráter pessoal para adquirir um fundamento legal.

A propósito, devemos a diferença entre constituição em sentidos formal e material, tão cara à doutrina constitucional, justamente à essa possibilidade de se manter um sistema materialmente absolutista ainda que com a adoção de uma forma constitucional. A constituição material assim é dita em termos de que se ocupa de fazer a diferenciação das tarefas do Estado e sua atribuição a diferentes órgãos de poder, com vistas a evitar a concentração de poder em um só indivíduo. Tratase da constituição autêntica que,em prevendo mecanismos para cooperação dos diversos detentores de poder político, termina por limitá-lo evitando, assim, abusos e interferências recíprocas daqueles que detém parcelas suas. 
Uma constituição em sentido material é, ainda, a norma fundamental que contém mecanismos planejados para a reforma constitucional e que possibilite, assim, uma adaptação pacífica da ordem às mudanças sociais e políticas e, por fim, que reconheça expressamente direitos individuais e liberdades fundamentais, prevendo a sua proteção contra a interferência de um ou de todos os detentores do poder político. Pensada em termos formais, diferentemente, a constituição é apenas a Lei Maior do Estado, a Lei fundamental de um povo enquanto o conjunto de regras jurídicas com máxima eficácia que visam a organização e funcionamento do Estado.

Não basta, portanto, pensar a constituição apenas em termos formais já que, dentro desse formalismo, caberiam inclusive as ditaduras constitucionais, apoiadas numa forma constitucional, mas de legitimidade apenas aparente - não são constituições autênticas, em sentido material. A constituição autêntica ou real será sempre uma conjugação de valores individuais e valores sociais que o próprio povo selecionou através da sua experiência concreta em um tempo e lugar determinados.

Estabelecida a necessidade de adoção, pelo Estado, de uma norma fundamental (Constituição), cabe destacar a existência de outra etapa fundamental para assentar o posicionamento da essencialidade de separar as funções (poderes) do Estado como forma de realizar as suas finalidades e, adicionalmente, preservar liberdades. Emergem, nesse sentido, as declarações de direitos, as quais, apesar de suas fragilidades - fruto essencialmente da inexistência de um órgão que fiscalize e puna o Estado em caso de inobservância dessas normas - devem ser aplicadas independente da sua inclusão nos direitos pátrios dos Estados.

\section{A SEPARAÇÃO DE PODERES- CRÍTICA AO SISTEMA DE FREIOS E CONTRAPESOS}

Concebida por Charles-Louis de Sécondat, o Barão de Montesquieu, no final do século XVIII, a doutrina da separação dos poderes do Estado foi incorporada pelo constitucionalismo inicialmente como forma de evitar a formação de governos absolutos e, assim, garantir a liberdade dos indivíduos (MENEZES, 2005, p.247). Mais adiante, no final do século XIX, serviu ainda como modelo para aumentar a eficiência do Estado pela distribuição de suas atribuições entre seus órgãos especializados, racionalizando o exercício do poder político. A ideia de fundo era, em síntese, que em desconcentrando o poder, enfraquecer-se-ia o Estado,admitindo-se sua interferência na vida social apenas como vigilante e conservador da ordem de coisas(DALLARI, 2018, p.213). Neste Sentido, dirá o Barão:

Há em cada Estado três espécies de poder: o poder legislativo, o poder executivo das coisas que dependem do direito das gentes, e o poder executivo daquelas que dependem do direito civil. Pelo primeiro poder, o príncipe ou magistrado cria as leis para um tempo determinado ou para sempre, e corrige ou ab-roga aquelas que já estão feitas. Pelo segundo, determina a paz ou a guerra, envia ou recebe embaixadas, estabelece a segurança, previne as invasões. Pelo terceiro, pune os crimes ou julga as questões dos indivíduos (MONTESQUIEU, 2006:165). 
A separação dos poderes do Estado significa, a grosso modo, a existência de muitos órgãos que exerçam o poder, e não que o poder do Estado seja dividido, afinal, a soberania é una e indivisível. (DALLARI, 2018, p.213). A necessidade de racionalizar o exercício do poder, limitando-o, já estava presente no pensamento de Aristóteles(MENEZES, 2005, p.246), na Antiguidade Clássica, segundo o qual seria injusto e perigoso que um só indivíduo exercesse o poder. No século XIV, em 1324, Marsílio de Pádua escreve "Defensor Pacis", estabelecendo a distinção entre os poderes. Na base de seu pensamento está a oposição entre o povo, a quem chama “primeiro legislador", e o príncipe, numa primeira tentativa de afirmação da soberania popular.

No século XVI, com a publicação de seu O Príncipe(1513), Nicolau Maquiavel identifica que na França já haveria três poderes distintos: o legislativo (Parlamento), o executivo (o rei) e um judiciário independente, algo que será mais elaborado posteriormente por John Locke, no século XVII, quando faz uma primeira sistematização doutrinária da separação de poderes. Locke aponta para a existência de quatro funções fundamentais a serem exercidas por dois órgãos do poder: A função legislativa caberia ao Parlamento ea função executiva cabia ao rei, desdobrando-se essa em função federativa - casos de poder de guerra e paz, ligas e alianças e todas as questões externas ao Estado - e numa quarta função, também prerrogativa de do rei, definida por ele como "o poder de fazer o bem público sem se subordinar a regras" - algo potencialmente perigoso já que poderia ser usado como pretexto para decisões absolutistas, embora Locke se opusesse a ele (MENEZES, 2005, p.247).

É apenas no século XVIII, contudo, com Montesquieu e seu O Espírito das Leis (1748), que a teoria da separação dos poderes é de fato concebida (DALLARI, 2018, p. 215). Concebendo um sistema que conjuga legislativo, executivo e judiciário harmônicos e independentes entre si, dirá Montesquieu que "tudo estaria perdido se o mesmo homem ou o mesmo corpo dos principais, ou dos nobres, ou do povo, exercesse esses três poderes"(MONTESQUIEU, 1962). O autor não concebe atribuições internas ao Estado, exceto julgar e punir os indivíduos que não cumprissem as leis. Trata-se do Estado mínimo que será consagrado mais adiante pelo liberalismo, não havendo grande preocupação com a sua eficiência até este momento, e sim com a garantia da liberdade individual.

Alguns anos após a publicação de O Espírito das Leis (1962), a Declaração de Direitos da Virgínia, em 1776, dirá em seu parágrafo quinto: "os poderes executivo e legislativo do Estado deverão ser separados e distintos do judiciário". No mesmo sentido, em 1789, a Declaração de Direitos do Homem e do Cidadão, 1789, dirá em seu artigo XVI: "toda sociedade na qual a garantia dos direitos não está assegurada, nem a separação dos poderes determinada, não tem Constituição".

Parece-nos claro, portanto, que a separação dos poderes do Estado - ou a sua divisão em funções - esteve desde o início associada ao Estado Democrático, dando origem posteriormente à "teoria dos freios e contrapesos", segundo a qual o Estado pratica atos de duas espécies, os chamados especiais e os chamados atos gerais. O Legislativo só pratica os atos gerais, emitindo regras abstratas e gerais, não atua concretamente na vida social. Depois de emitida a norma geral 
aí sim é que se abre a possibilidade de atuação pelo poder executivo, através de atos específicos, regulatórios. $\mathrm{O}$ executivo dispõe de meios concretos para agir, mas está limitado pelos atos gerais praticados pelo legislativo, onde a democracia efetivamente "mora". Havendo exorbitância de qualquer dos poderes surge então a ação fiscalizadora do judiciário. Dentro desta lógica, cada poder permanece dentro dos limites da sua esfera de competência.

Em que pese um tal sistema permitir a separação e consequente racionalização/limitação do exercício do poder político do Estado, a separação entre eles não é real. Legislativo, executivo e judiciário se interpenetram a todo instante, sendo essa uma separação apenas formal. Embora tenha garantido a limitação do poder político, o sistema não conseguiu de fato assegurar o caráter democrático do Estado e a liberdade dos indivíduos - apenas a de poucos privilegiados. Não é raro que se vejam executivos antidemocráticos e legislativos sem representatividade ou seja, antidemocráticos, quando formulam atos gerais que obedece às determinações e conveniências do executivo e não aos anseios do povo que representa.

Se num primeiro momento a separação dos poderes foi pensada para enfraquecer o Estado, com a evolução da sociedade isso foi se tornando mais complexo na medida em que esse mesmo Estado foi sendo mais e mais demandado, exigindo-se uma legislação mais numerosa e mais técnica, incompatível com os modelos de separação de poderes. Coloca-se, então, a questão da eficiência do Estado e de como garanti-la sem atentar diretamente contra a separação dos poderes. Algumas soluções pensadas para resolver essa equação foram, por exemplo, a gradual delegação de poderes do poder legislativo pelo texto constitucional, com limitações quanto ao tempo e objeto; e a transferência constitucional de competências por meio de reforma constitucional (emenda) ou pela promulgação de novas Constituições. Em todos os casos, há que se atentar para uma tendência de manutenção da teoria dos freios e contrapesos apenas na aparência, aumentando as competências do executivo e reduzido as do legislativo, na formação da vontade do Estado.

Fica claro, portanto, que, em que pese a teoria dos freios e contrapesos figurar como uma importante ferramenta ou sistema para assegurar o caráter democrático do Estado e as liberdades dos indivíduos, tais exigências requerem do Estado um maior dinamismo e sua presença constante na vida social, vale dizer, é preciso que ele possa conciliar a necessidade de eficiência com os princípios democráticos, algo que se incompatibiliza muitas vezes com a tradicional separação de poderes.

Dito de outro modo, embora a teoria da separação dos poderes seja um dos mais importantes alicerces do Estado de Direito, é importante atentar para o fato de que na contemporaneidade há uma evidente modificação do sistema de freios e contrapesos que visa equilibrar as funções do Estado. Fundamentalmente, a função legislativa tem sido o alvo preferencial de excessos cometidos pelos dois outros poderes. Ora o Judiciário se arvora em funções no limite legislativas, quando o STF é chamado a tratar de questões como, por exemplo, a prisão após condenação em segunda instância - o que se convencionou chamar de ativismo judicial - ora o Executivo se agiganta pelo excesso de medidas provisórias. 


\section{INGEBORG MAUS E O JUDICIÁRIO COMO SUPEREGO DA SOCIEDADE: EXCESSOS QUE AMEAÇAM AS LIBERDADES?}

A cientista política Ingeborg Maus discorre sobre o papel do poder judiciário em uma sociedade considerada órfã com a perda da importância que a figura paterna na definição do ego, conforme aponta Herbert Marcuse (MAUS, 2000, p.184). Nesse contexto, a construção da consciência individual é fortemente determinada por diretrizes sociais esvaziando, segundo a autora, a capacidade de crítica autônoma das normas sociais (MAUS, 2000, p. 185), daí afirmar-se a existência de uma sociedade órfã na qual indivíduos e coletividade alcançam a condição de meros objetos administrados que passam a venerar a representação da Justiça (MAUS, 2000, p.185).

Mediante tal cenário, a pessoa do juiz personifica os pressupostos de decisões racionais e justas (MAUS, 2000, p.185), sendo assim, tal personalidade passa a representar não só uma formação ética exemplar, mas, também a ser compreendida como requisito de decisões consideradas justas (MAUS, 2000, p.186). Para Ingeborg Maus "não é difícil reconhecer o clássico modelo de transferência do superego" (MAUS, 2000, p.186) tampouco identificar em tal compreensão a centralização da consciência social na Justiça (MAUS, 2000, p.186).

Tal constatação acende um alerta quando da leitura da obra de Maus para a imunização da atividade jurisprudencial perante toda e qualquer crítica (MAUS, 2000, p.187), o que aponta para sua fuga de qualquer mecanismo de controle social, controle ao qual, sabidamente, toda instância estatal precisa ser subordinada no bojo de um Estado Democrático de Direito. Chamamos a atenção, nesse ponto para a questão que suscitamos neste trabalho, qual seja, a da tripartição de poderes como elemento imprescindível para as liberdades democráticas, tendo em vista que tal situação demonstrada pela cientista política alemã nos revela que o judiciário, nesses termos, passa a encarnar "o próprio monarca substituído" nas palavras de Maus (2000, p.187). Nessa toada, o que vemos é a auto-ampliação dos poderes do judiciário, sem limites definidos e que libera a justiça de uma sintonização com a vontade popular (MAUS, 2000, p.189) que resulta na transformação de espaços de liberdade dos indivíduos em "produtos de decisão judicial fixados caso a caso" (MAUS, 2000, p.190).

É interessante, considerando o mote do presente manuscrito, considerar o papel reservado ao parlamento no bojo do ativismo constitucional delineado por Maus no texto em análise. Para ela, "o Parlamento aparece agora como simples representante do entrechoque de impulsos e energias sociais, cujo excesso tem como censor a Justiça.” (MAUS, 2000,p.195), marcado socialmente por um suposto déficit de conhecimento jurídico.

Na perspectiva de Maus, o Tribunal Constitucional Alemão(TFC), análogo ao nosso Supremo Tribunal Federal (STF), tem alargado de tal maneira as suas atribuições, que podemos chegar ao limite 
daprópriaConstituiçãopodereventualmenteserconsideradainconstitucional, havendo,portanto, algo como direitos "suprapositivos" (MAUS, 2000, p.191) e auto-fundados. Nesse sentido, o Judiciário, a quem Montesquieu não deu muita importância, seria alçado a uma posição de monarca absoluto, fundando-se algo como uma "teologia constitucional”, com os juízes como sábios interpretando o texto sagrado (MAUS, 2000, p.192). Tornam-se uma elite nacional, deixando à mostra uma crença de que a lei vincula seus destinatários, não seus intérpretes (MAUS, 2000, P.198). Rompendo com o equilíbrio entre os poderes, a contemporaneidade tem assistido ao Judiciário se transformar em uma espécie de religião civil. Segundo Maus, portanto e em síntese, o Judiciário tornou-se um novo superego ${ }^{3}$ da sociedade. Um novo superego que está na administração judicial da moral.

, ao analisar o artigo de Ingeborg Maus, a professora Gisele Cittadino (2002,p.141) assevera que:

O que nos resta agora perguntar é se o vínculo entre ativismo judicial e reforço da lógica democrática, que subjaz ao processo de "judicialização da política", pode viabilizar essa quebra de limites normativos à soberania popular, por mais legítimo que seja o movimento político a dar-lhe sustentação. Em outras palavras, a indagação é se o Poder Judiciário, para não violar a deliberação pública de uma comunidade política que atua autonomamente orientada pelos valores que compartilha, deve ou atuar como regente republicano da cidadania ou abdicar de garantir direitos constitucionalmente assegurados. Dar uma resposta positiva a essa pergunta significa, na verdade, autorizar os tribunais, especialmente as cortes supremas, a atuar como profetas ou deuses do direito, consolidando aquilo que já é designado como "teologia constitucional" e imunizando a atividade jurisprudencial perante a crítica a qual originariamente deveria estar sujeita

Nesse diapasão, Cittadino reconhece a necessidade de uma interpretação construtivista, destacadamente das normas e princípios, presente nas Constituições das democracias contemporâneas, contudo, destaca que a recorrência dessa "dimensão inevitavelmente criativa da interpretação constitucional" (CITTADINO,2002, p.141) em todo e qualquer processo hermenêutico não incorre, necessariamente, em prejuízo à lógica de separação de poderes. Mesmo quando os tribunais precisam ultrapassar, em suas decisões, aquilo que está consignado em nosso ordenamento jurídico, devem "proferir decisões corretas e não se envolver na tarefa de criação do direito" (CITTADINO, 2002, p. 141).

Nesse sentido, considerando a liberdade, recorte do presente trabalho, é importante estabelecer que este é um direito fundamental previsto na Constituição Cidadã de 1988. Desse modo, é imprescindível dentro da discussão em curso atentar para a vinculação dos poderes públicos aos direitos fundamentais que se posicionam no ordenamento jurídico também como "parâmetros de organização e de limitação dos poderes constituídos" (MENDES; BRANCO, 2011, p.167). Gilmar Mendes e Paulo Gonet Branco são categóricos ao afirmar que "a constitucionalização dos direitos fundamentais impede que sejam consideradas meras autolimitações dos poderes constituídos (...)

3 O superego designa uma das três instâncias dinâmicas do aparelho psíquico para a teoria psicanalítica. Trata-se de parte moral da psique e que representa valores sociais e onde ocorre a castração do desejo. 
passíveis de serem alteradas ou suprimidas ao talante destes" (MENDES; BRANCO, 2011, p. 167).

\section{CONCLUSÕES}

Como visto, o pensamento de Montesquieu sobre a separação de poderes visava assegurar liberdades, entretanto, sua preocupação parece-nos não ter encontrado eco na forma como o poder judiciário se consolidou no Brasil - e também em outros lugares do mundo, como a própria Alemanha de Maus. Parece-nos interessante a contraposição do papel assumido pelo judiciário na atualidade, bem delineado no texto de Maus, em detrimento do papel reservado por Montesquieu ao poder que se incumbiria de pronunciar as normas elaboradas pelo legislador.

Compreendemos também não ser difícil entender a supremacia do judiciário em detrimento de outros poderes, tendo em vista a conturbada relação de seu povo com a política e a trajetória democrática brasileira.

A referida tensão foi agravada nos últimos anos em virtude de episódios de corrupção envolvendo membros dos poderes executivo e legislativo, em âmbito federal e estaduais, descortinados pelo poder judiciário. Em que pese uma crítica ao modo, por vezes suspeito e até mesmo contraditório às premissas constitucionais, como, por exemplo, o uso do plea bargain na Operação Lava Jato, assuntos que por si só ensejam outro manuscrito, é inegável o fortalecimento deste poder em detrimento dos outros dois que saíram, no conjunto, bastante desacreditados pela população.

A estabilidade do regime ideal está em que a correlação entre as forças reais da sociedade possa se expressar também nas instituições políticas. Isto é, seria necessário que o funcionamento das instituições permitisse que o poder das forças sociais contrariasse e, portanto, moderasse o poder das demais. Assim compreendida a teoria dos poderes de Montesquieu se torna extremamente contemporânea, por apontar a necessidade de arranjos institucionais que impeçam que alguma força política possa a priori prevalecer sobre as demais, reservando-se a capacidade de alterar as regras depois de jogado o jogo político.

\section{Referências Bibliográficas}

BONAVIDES, Paulo. Curso de Direito Constitucional. 23a edição. São Paulo: Malheiros, 2008.

CITTADINO, Gisele- Poder Judiciário, ativismo judicial e democracia. Revista da Faculdade de Direito de Campos, ano II, nº e ano III, n³, 2001-2002.

DALLARI, Dalmo de Abreu.Elementos de Teoria Geral do Estado. $33^{\mathrm{a}}$ edição $5^{\mathrm{a}}$ tiragem São Paulo: Saraiva, 2018.

HOBBES, Thomas. Leviatã ou a matéria, forma e poder de um estado eclesiástico e civil. $4^{\mathrm{a}}$ ed. São Paulo: Nova Cultural, 1988. 
MAQUIAVEL, Nicolau. Comentários sobre a primeira década de Tito Lívio. Tradução de Sérgio Bath. Brasília: Editora da Universidade de Brasília, 1994. $3^{\text {a }}$ edição.

MAUS, Ingeborg.Judiciário como superego da sociedade - o papel da atividade jurisprudencial na “sociedade órfâ", Novos Estudos, CEBRAP, No.58, Nov.2000, pp.183-202.

MENDES, Gilmar Ferreira; BRANCO, Paulo Gustavo Gonet Branco. Curso de Direito Constitucional. $6^{\text {a }}$ edição. São Paulo: Saraiva, 2011.

MENEZES, Aderson. Teoria Geral do Estado. $8^{a}$ edição. Rio de Janeiro: Editora Forense, 2005.

MONTESQUIEU, Barão de. Do espírito das Leis. Ed. Martins Fontes, São Paulo, 2000.

Recebido em:05/06/2020

Aprovado em :18/06/2020 